\title{
A BENEFIT-COST MODEL FOR THE EVALUATION OF ON-SITE BENEFITS OF SOIL CONSERVATION PROJECTS IN MEXICO
}

\author{
Gunter Schramm*
}

\begin{abstract}
Soil and water conservation measures can comprise a wide range of activities, both structural and non-structural. Their potential benefits range from protection and productivity increases of the directly affected lands to widely dispersed downstream benefits. While in most situations it is rather difficult to evaluate the latter, it can be shown that in many cases the direct upstream benefits are sufficiently large to justify soil and water conservation programs regardless of potential additional downstream benefits. A benefitcost model was developed that compares program costs per unit of directly protected agricultural land with the net benefits resulting from two on-site consequences, land productivity enhancement from improved water conservation and elimination of productivity losses from gradual soil destruction. This model was applied to ongoing governmental programs in two Mexican states. The results show that benefits from the prevention of soil destruction are substantially larger than those from immediate productivity increases, although the latter were considered by Mexican authorities to represent the major program benefits.
\end{abstract}

\section{Introduction}

Soil Conservation projects can consist of a wide variety of activities. These may range from non-structural ones such as giving advice to farmers about soil management and farming practices, to the construction of elaborate protective works on a regional watershed basis. Frequently, a combination of non-structural and structural means will be needed to yield optimum results, but in other cases some specific types of activities may well represent viable or even better substitutes for others. For example, farming practices such as contour plowing, or non-tillage planting with herbicide applications in some locations may well be more effective means of soil erosion control than the customary terrace construction, gully protection and/or soil ripping

* Professor of Resource Economics, The University of Michigan, School of Natural Resources, USA. I want to thank Sydney A. Draper and August T. Schumacher for helpful suggestions. 
activities. ${ }^{1}$ While the Benefit/Cost model presented below was designed specifically to evaluate the latter types, it could be easily adopted to the evaluation of all others as well. The empirical data utilized refer to two regions in Mexico in which precipitation is generally a limiting factor to non-irrigated crop production.

\section{Types of Benefits}

Four types of benefits may flow from soil conservation activities. The first, and most obvious one, is the increase in the productivity of the protected farm or range land. This increased productivity will generally be the result of improved moisture retention capability of the soil, and of avoidance of crop losses from excess water flows or wind damage. These benefits have been explicitly evaluated in the $\mathrm{B} / \mathrm{C}$ model below.

The second type of benefits may result from cost reductions in tilling, planting, weeding, and harvesting operations, including potential reductions in the amounts of fertilizers or herbicides required. However, by the same token, certain soil conservation practices could also lead to an increase in direct farm operating costs, as for example the practice of contour plowing as compared to straight furrow plowing. The question whether overall costs will increase or decrease is an empirical one and must be evaluated on a case by case basis. No specific allowance has been made in the model for these potential benefits or costs since no data were available on their potential magnitude or significance. However, they could be easily incorporated by adjusting the respective net values of output for the with and without cases.

The third type of benefits, and, as the empirical results of the model indicate, probably most important type, stem from the protection of the continued productivity of the soil itself. In the absence of erosion control measures, the productive potential of a given parcel of land will gradually diminish and eventually be destroyed entirely through the continuing loss of its topsoil. ${ }^{2}$ Prevention of this loss, therefore, is a direct benefit of the protective measures and must be counted as a benefit. The magnitude of these benefits will vary depending on the rate at which the topsoil is destroyed. In general, the shorter this time-span the greater the benefits will be. As can be seen from Table II a time-span of 25 years to total destruction of a given parcel of land would result in overall internal rates of return of 10 and $16 \%$ in the Aguascalientes or Oaxaca examples respectively, while they would increase to 11 and $18 \%$ if the

${ }^{1}$ For a detailed discussion of the advantages of non-tillage planting as a soil conservation strategy see $4, \mathrm{pp} .28-33$. The various types of tillageconservation practices used throughout the United States and Canada have been discussed in 9 regional-oriented articles in (5, pp. 5-65).

${ }^{2}$ Under U.S. conditions, it was estimated that in order to maintain soils indefinitely, maximum allowable soil losses should not exceed 12.5 tons per hectare in deep and 2.5 tons in shallow soils. From: $(1, p .147)$. 
time span is reduced to 15 years. 3 However, it should be noted that these findings are based on the assumption of equal costs for protective works and maintenance. In situations where differences in erosion rates are a function of the slopes of the land, increased steepness, for example, will generally result in increased costs for protective works as well. As a result, the internal rates of return would decline.

Finally, the last type of benefits would consist in the reduction of losses resulting from offsite, downstream effects. These off-site damages may consist of increased turbidity of rivers which could interfere with aquatic life, increased flood damages, or increased sedimentation rates of reservoirs and water courses. No attempt has been made in the model to account for these types of benefits. This omission may be justified in regions where erosion control measures will be limited to areas which are quite small compared to the size of the watershed in which the protected area or areas are located. The potential contribution to total sediment flow of these protected areas, hence, also are likely to represent only a small fraction of the total, so that their addition or deletion would have little effect on overall downstream damages. However, in some areas where agricultural land is extensive, contiguous and subject to erosion, control measures covering all land may bring about a significant change in overall downstream damages. In these cases explicit evaluation of these benefits would be called for. As a recent study has found, for example, in Illinois farming areas on-site benefits to farmers were only about $1 \%$ of private net income, while benefits from prevented damages off-site ranged between 9 and $16 \% .^{4}$

\section{Types of Costs}

The types of costs included in the model are the conventional ones such as construction, land preparation (ripping) and planting costs for the various structural measures as indicated, and maintenance and repair expenditures on a fixed annual basis. For the latter constant prices were assumed. The former were assumed to be undertaken in year one on the assumption that all investment-type activities would be completed in less than a year. If necessary, this assumption could be easily changed, of course.

No special allowance was made for administrative overhead costs, project planning and design costs, costs of farmer education, and costs of continuing supervision of completed works by the Soil Conservation Service. It was assumed that proper allowances for these categories were included by the Mexican Soil Conservation Service in its tabulated per-hectare costs. Obviously, at least to the extent that these costs are separable (i.e., project specific), they have to be included in any Benefit-Cost evaluation of a given project.

${ }^{3}$ Assuming infinite life in the case of protection.

${ }^{4}$ See (3, pp. 117-126). 
No special allowance was made for any un- or underemployment benefits through the use of explicit shadow wage rates. Such allowances may be appropriate if project activities are limited to the slack employment period in the dry season. During the wet season, rural employment opportunities reach or sometimes even exceed the available labor supply in Mexico. 5 As can be seen from Table II, the conventional types of activities (i.e., terrace construction, etc.) are less costly with the use of machinery instead of hand labor. However, almost all projects undertaken in Mexico utilize the latter whenever possible. This already implies a significant contribution towards national employment objectives and, hence, are akin to the use of shadow wages if the economic evaluation is based on the lower-cost machinery alternative. For example, according to the Soil Conservation Service, unskilled labor costs on projects built with hand-labor account for $85 \%$ of total costs, while the use of tractors and machinery reduces labor costs to $20-30 \%$ of the total. Given the range of cost differentials between the tractor-built and hand-built works (see Table I), this implies a shadow wage rate of about 0.60 for the Aguascalientes and 0.57 for the Oaxaca cases respectively.

\section{MEXICO}

TABLE I

PHYSICAL CHARACTERISTICS, CURRENT COSTS, AND EFFECTS ON AGRICULTURAL PRODUCTIVITY OF SOIL CONSERVATION MEASURES IN AGUASCALIENTES AND OAXACA*

\begin{tabular}{lcc}
\hline \hline & Aguascalientes & Oaxaca \\
\hline Average Slope & $6-8 \%$ & $8-10 \%$ \\
Maximum rainfall in $24 \mathrm{hr}$. period & $70 \mathrm{~mm}$ & $75-78 \mathrm{~mm}$ \\
Soil depth & $15-30 \mathrm{~cm}$ & $10-30 \mathrm{~cm}$ \\
State-wide average maize yield/ha. & $463 \mathrm{~kg}$. & $754 \mathrm{~kg}$. \\
Average costs per ha. , terrace construction & & \\
$\quad$ by manual labor w. gully check dams & $\$ 211 / \mathrm{ha}$. & $\$ 176 / \mathrm{ha}$. \\
Average costs per ha., terrace construction & & \\
w. tractor incl. gully check dams & $\$ 139 / \mathrm{ha}$. & $\$ 111 / \mathrm{ha}$. \\
Planting costs of Maguey & $\$ 39 / \mathrm{ha}$ & $\$ 64 / \mathrm{ha}$. \\
Deepsoil plowing (by tractor) & $\$ 70 / \mathrm{ha}$. & $\$ 80 / \mathrm{ha}$. \\
Estimated increase in production of maize: & & \\
- Terraces only & $25 \%$ & $25 \%$ \\
- Subsoil plowing on terraces & $40 \%$ (total) & $40 \%$ \\
- Subsoil plowing only & $20 \%$ & $20 \%$ \\
\hline
\end{tabular}

Source: Direction General de Conservacion del Suelo y Agua, July 1976.

$*$ All peso costs converted at US $\$ 1.00=$ Mex. $\$ 12.50$.

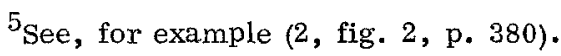




\section{Net Benefits from Erosion Control Measurements ${ }^{1}$}

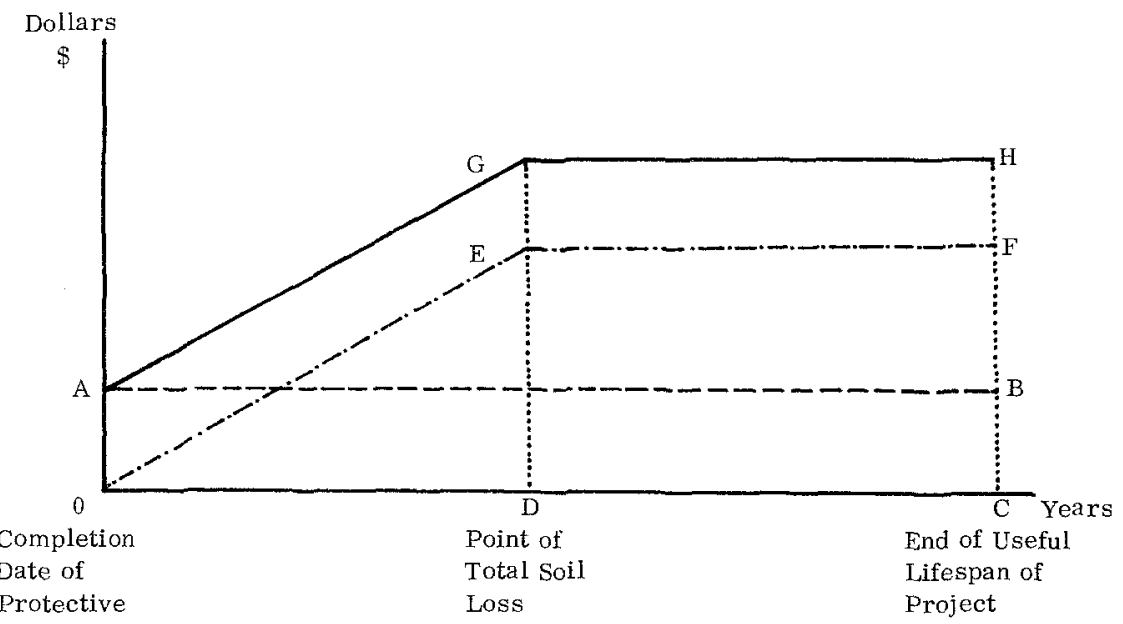

Works

where:

OABC Net increase of the value of output of protected land per hectare minus costs of repair and maintenance;

OED Net benefits per hectare from the avoidance of increasing soil losses up to the point of total destruction;

DEFC Net benefits per hectare from the maintenance of the original productivity of the protected land;

OAGHC Total net benefits per hectare from soil conservation measures.

\footnotetext{
${ }^{1}$ Net of any changes in farm production costs resulting from conservation
} measures. 


\section{The B-C Model}

The model for evaluating the benefits and costs of soil erosion control measures and for finding the internal rates of return is the conventional one, i. e. , it is solved for the rate of return that will equalize the respective benefit and cost streams. The types and time streamof the benefits included in the model have been shown graphically in figure 1 .

As can be seen, total benefits over time consist of two components. The first is the addition to net output of the protected land, minus the maintenance and repair expenses for the soil erosion control measures. The second consists of the prevention of soil losses, and hence, the reduction in the value of the original net output (i.e., value of gross output minus farm production costs). In the absence of more accurate information it was assumed that this reduction in basic output would proceed linearly up to the point of total soil loss or land abandonment. ${ }^{6}$ If only partial land destruction is likely to occur at a given site, the percentage of expected soil loss should be multiplied with the original net value of output.

Mathematically, the model takes the following form:

$$
\text { (1) } e\left[\frac{(b-f) g}{i}-\left(\frac{(b-f) n g}{i}\right)\left(\frac{i}{(1+i)^{n}-1}\right)\right]\left[\frac{(1+i)^{n}-1}{i(1+i)^{n}}\right]+
$$

Present value of benefits from the prevention of soil + destruction up to the year of total soil destruction.

$$
e\left[\frac{1}{(1+i)^{n}}\right]\left[(b-f) \frac{(1+i)^{t-n}-1}{i(1+i)^{t-n}}\right]+\left[(a-m) \frac{(1+i)^{t}-1}{i(1+i)^{t}}\right]-
$$

Present Value of benefits from the prevention of soil destruction after the year of final soil destruction

$$
\text { c }
$$

Present value of investment costs
Present Value of increase in net productivity of the protected land.

$$
=\quad 0
$$

and the equation is solved for $i$, the internal rate of return. ${ }^{7}$ soil losses as a function of a number of physical characteristics such as soil type, slope, slope length, rainfall, rainfall intensity, agricultural practice etc. Empirical verification would be needed to transfer these estimated relationships to other climatic and geomorphological zones, however. For a discussion of the advantages and shortcomings of these estimating techniques see, for example: (6, pp. 5-9).

${ }^{7}$ The product of $\mathrm{n} \mathrm{g}$ in the second term is always equal to 1 since $\mathrm{g}$ is the inverse of $n$. 
where:

$\mathrm{e}=$ the coefficient of total destruction of the land subject to protection (equal to 1.0 in the case of total destruction); 8

$b=$ the original annual gross value of output per hectare of the land to be protected;

$\mathrm{f}=$ net farm production costs per hectare;

$\mathrm{g}=$ the uniform gradient of estimated soil losses, equal to $1 /$ (years to total soil destruction);

$\mathbf{i}=$ the internal rate of return;

$\mathrm{n}=$ the number of years to total destruction;

$t=$ the life expectancy of the project in years;

$a=$ the additional net value of output per hectare resulting from soil protection measures;

$\mathrm{m}=$ the annual maintenance and repair expenditures of the protective works per hectare of protected land;

$\mathrm{c}=$ the per hectare investment costs of the project.

Mathematically the first expression represents the present value of a uniform gradient. The expression $i /(1+i)^{n}-1$ contained in it is the normal sinking fund factor whose value can usually be found in financial tables. Also, the expression $(1+i)^{n}-1 / i(1+i)^{n}$ is the present worth factor of a uniform series which also can be found in financial tables. $1 /(1+\mathbf{i})^{\mathrm{n}}$ represents the present value of a single (future) payment.

If the analysis is to be based on the assumption of an infinite life expectancy for the project, equation (1) reduces to

(2) $\mathrm{e}\left[\frac{(\mathrm{b}-\mathrm{f}) \mathrm{g}}{\mathrm{i}}-\left(\frac{(\mathrm{b}-\mathrm{f}) \mathrm{ng}}{\mathrm{i}}\right)\left(\frac{\mathrm{i}}{(1+\mathrm{i})^{\mathrm{n}-1}}\right)\right]\left[\frac{(1+\mathrm{i})^{\mathrm{n}}-1}{\mathrm{i}(1+\mathrm{i})^{\mathrm{n}}}\right]+$

$$
e\left[\frac{1}{(1+i)^{n}}\right]\left[\frac{b-f}{i}\right]+\frac{a-m}{i}-c=0
$$

Because of their complexity these equations have to be solved either by iteration or with the aid of a computer.

Example:

The following example is based on the data of Tables I and II for Aguascalientes. Life expectancy (a) 30 years, (b) infinity, terrace construction by hand plus maguey planting, total soil loss over a 20 year period.

The variables take on the following values:

$$
\begin{aligned}
& \mathrm{e}=1.0 \\
& \mathrm{~b}=(0.463 \mathrm{~kg})(\$ 152.00)
\end{aligned}
$$

${ }^{8}$ Assumed to be equal to 1.0 in the calculations underlying the data of Table II. 


$$
\begin{aligned}
\mathbf{f} & =0.4(0.463)(\$ 152.00) \\
\mathrm{g} & =1 / 20 \\
\mathrm{n} & =20 \text { years } \\
\mathrm{t} & =\text { (a) } 30 \text { years; (b) infinity } \\
\mathrm{a} & =0.25(0.463 \mathrm{~kg})(\$ 152.00) \\
\mathrm{m} & =\$ 8.00 \\
\mathrm{c} & =(\$ 211.00+\$ 39.00)=\$ 250.00
\end{aligned}
$$

Substituting these data in equations (1) and (2) and solving for i results in

$$
\begin{aligned}
& \text { if } t=30 ; \mathbf{i}=10.5 \% \\
& \text { if } t=\text { infinity; } \mathbf{i}=10.7 \%
\end{aligned}
$$

What the data of Table II clearly indicate is that the larger part of overall on-farm benefits accrue from the prevention of soil productivity losses rather than from net increases in annual outputs. In terms of gross benefits, roughly one-third of them are the result of increased productivity, with the other twothirds representing damages prevented. 1 Obviously these relationships reflect the specific Mexican conditions to which the model was applied. Nevertheless, even if these percentages were to be different in other regions, damages prevented are likely to represent the largest portion of benefits that could be expected.

Another finding, which was rather surprising to the Soil Conservation Service, was that deep-soil ripping either by itself or in combinations with terrace construction is an uneconomic proposition in the two regions. This was a consequence of the need to repeat the operation every four years.

The importance of soil loss prevention for total benefits has significant policy implications. Since the majority of landholders in erosion-prone regions are subsistence farmers, they are unlikely to be able to pay the full costs of the protective measures because most of the expected benefits do not result in an income increment, but only in a prevention of future income reductions.

This has further implications for the coverage of maintenance costs. The above model, by allowing for reasonable maintenance expenditures, assumes that they would actually be undertaken and soil losses permanently prevented. Mexican experience shows that this is frequently not the case. Many of the government-sponsored and financed erosion control works, whose maintenance were turned over to beneficiary-associations, have quickly fallen into disrepair. This means, of course, that projected benefits are not being realized. An added cost, therefore, may well be the need to form a supervising agency that would enforce and control maintenance. This would reduce overall social net benefits. However, the other alternative would be a much more rapid destruction of agricultural land that in some fashion offers some form of livelihood to its owners. This would result in even greater migration flows of destitute farmers to overcrowded cities that are totally unable to cope with this influx.

\footnotetext{
$1_{\text {These percentages vary to some extent, of course, with the assumed }}$
} number of years to total soil loss. 


\section{INTERNAL RATES OF RETURN FOR REPRESENTATIVE SOIL EROSION CONTROL PROGRAMS IN AGUASCALIENTES AND OAXACA}

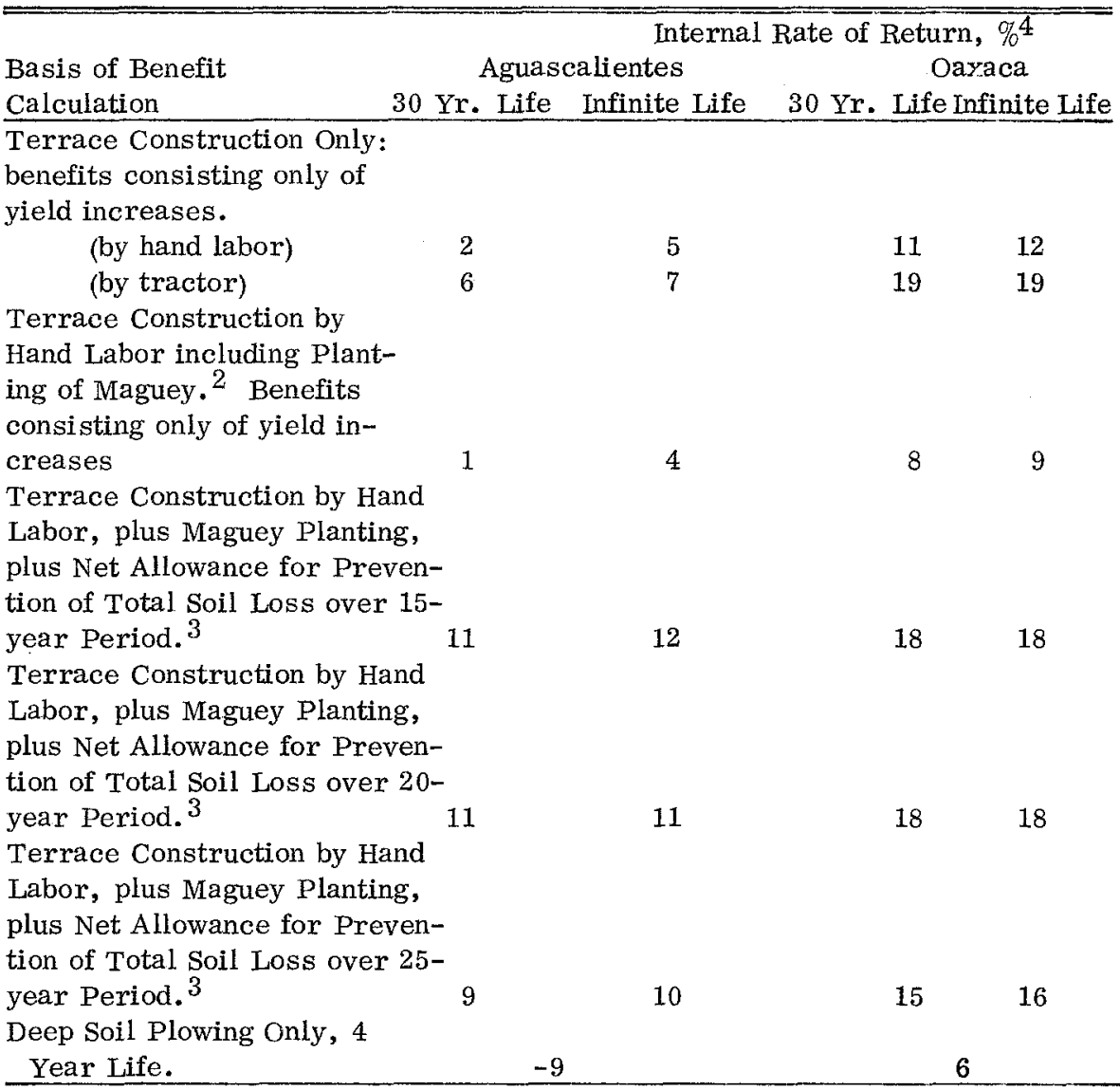

1. Data from Table I. All calculations assume either a 30-year or infinite life expectancy except for ripping operations which, according to the soil Conservation Service, have to be repeated every four years. Operating and maintenance costs (except for ripping) are assumed to amount to Mex. $\$ 100.00$ (U.S. $\$ 8.00$ at old exchange rate) per hectare per year.

2. Planting costs for Nopal are higher (see Table I) but would possibly be offset by partial harvesting and utilization when plants mature.

3. Assumes that continuing soil losses would destroy $6.7 \%, 5 \%$ or $4 \%$ of the original area under cultivation every year. Net agricultural income assumed to amount to $60 \%$ of gross income. Values of maize per ton $=\mathrm{Mex}$ $\$ 1900$ (U.S. $\$ 152.00$ at old exchange rate).

4. Rounded to the closest full percentage point. 


\section{REFERENCES}

1. Barlow, Thomas: "Solving the Soil Erosion Problem," Journal of Soil and Water Conservation, Vol. 32, No. 4, July-Aug. 1977.

2. Duloy, J. H., Norton, R. D. "CHAC Results: Economic Alternatives For Mexican Agriculture, " in L. M. Goreux, A. S. Manne, Multi-Level Planning: Case Studies in Mexico, North Holland, Amsterdam, 1973.

3. Gunterman, Karl E., Lee, Mint T., \& Swanson, Earl R. "The Economics of Off-Site Erosion," The Annals of Regional Science, Vol. X, No. 3, Nov. 1976.

4. Triplett, Glover B. Jr., Van Doren, David M., "Agriculture Without Tillage" Scientific American, 236-1, Jan. 1977.

5. Various Authors, "Conservation - Tillage, "Journal of Soil and Water Conservation, Vol. 32, No. 1, Jan.-Feb. 1977.

6. Wishmeier, W. H., "Use and Misuse of the Universal Soil Los Equation," Journal of Soil and Water Conservation, Vol. 31, No. 1. Jan.-Feb. 1976. 